\title{
THE INFLUENCE OF LAND USE AND MANAGEMENT MEASURES ON THE QUALITY OF GRASSLAND SOIL
}

\author{
WANG, K. ${ }^{1}-$ JIAO, Z. ${ }^{2}-$ TIAN, X. $.^{1,3^{*}}-$ FAN, H. $^{1}-$ ZHANG, F. ${ }^{1}-$ LI, Y. ${ }^{1}$ \\ ${ }^{1}$ The Agriculture of Shihezi University, 832000 Xinjiang, Shihezi, China \\ ${ }^{2}$ College of Biology and Geography, Yili Normal University, 835000 Xinjiang, China \\ ${ }^{3}$ College of Agriculture and Forestry, Hebei North University, 075000 Zhangjiakou, Hebei, China \\ *Corresponding author \\ e-mail:wky20@163.com \\ (Received 27 $7^{\text {th }}$ Feb 2019; accepted $3^{\text {rd }}$ May 2019)
}

\begin{abstract}
Improper conversion of grassland utilization patterns leads to soil quality degradation and increased soil erosion. Analysis of the differences and sensitivities of soil physical, chemical and biological quality indicators under different agricultural management practices, research with the development of Xinjiang YiLi Nalati representing the natural grassland grazing grassland, conventional farming and organic farming fields as the research object. The results showed that the degeneration of soil chemical mass will be much more to see for grazing mode. The most sensitive chemical quality index is soil total nitrogen and organic carbon, especially $0.25-2 \mathrm{~mm}$ and $2-8 \mathrm{~mm}$ soil organic carbon content. The farmland cultivation mode stimulates the soil microorganism's ability of absorbing carbon and nitrogen, which goes against the soil carbon and nitrogen's conservation especially for a long-term fertilizer application in the regular farming mode.
\end{abstract}

Keywords: conventional farming, organic farming, land use, lawn, soil quality

\section{Introduction}

Many ecological processes by nature and humans such as vegetation succession, the changes of land use pattern, have influences on the changes of the soil quality. The most profound and directive factors are utilization pattern of soil and the level of management. On the one hand, these factors can lead to soil degradation, soil erosion. On the other hand, they can improve the soil quality and ecological environment. Nowadays, the main reason of the soil degradation is that unreasonable way of land utilization used by humans. There is not a single or multiple index could reflect the combined action between the soil organisms, physics and chemistry. So, there is not established a uniform soil measurement. After many small watershed are developed, the land utilization begins to be diversity. The changes of the soil environment lead to that the function and structure of the ecosystem begin to change. The situation of the soil quality not only reflect the influences of the soil utilization on the soil physics, chemistry and soil quality, but also clear and definite the influences that decision of the soil utilization has on the nutrient cycling, leaching, soil structure, carbon accumulation and other related process.

The change of land to make it arable, which makes the soil organic matter lower. The transformation of arable land from woodland or grassland makes the soil property depredated (Meriles et al., 2008; Chen et al., 2008). For the ecologically fragile area, the soil parent material (parent material), altitude (altitude) and the use of a greater impact on soil properties, which affect the most is how to use the land (Fermont et al., 2008). In recent years, because of the overdevelopment of some where's water and land resource in Ili Valley, the valley terrace pastures which mainly used for animal husbandry degenerate 
seriously and is becoming the soil and water loss of the basin becoming more and more serious. Yang and Zhang (Yang and Zhang, 2009) analysis the use of change in cross-strait land of the Ili Valley, compared with the year of 1985, the arable land increases of $4.99 \times 10^{4} \mathrm{hm}^{2}$ entirely. Grassland is the only type of land which is reducing, whose reduced area contains $7.02 \times 10^{4} \mathrm{hm}^{2}$. The conversion from grassland to cropland accounted for $90.4 \%$. Because of the land development utilization improperly, the net increase of the useless land is $1.07 \times 10^{4} \mathrm{hm}^{2}$, the net increase of the saline land is $13.04 \times 10^{4} \mathrm{hm}^{2}$, which all of them cause a series of environmental problems of soil erosion and desertification and salinization. As is regarded to be the research object from the soil in Ili Nalati prairie and developed different kinds of land utilization on soil, the research on grassland development made it a theory evidence to Grazed Grassland, conventional field and organic field on the impact on soil quality and the rational exploitation of regional grassland resources definitely. The research also helps growers make the appropriate land management measures to adjust with.

\section{Materials and methods}

\section{Basic situation of region}

The study area located at long-term observation sites of grassland management central station of Yili State (North latitude $43^{\circ} 18^{\prime}-43^{\circ} 22^{\prime}$, East longitude $84^{\circ} 05^{\prime}-84^{\circ} 09^{\prime}$ ). The grassland was located in Piedmont plains of altitude $1480 \mathrm{~m}$, perennial resistance to low temperature and drought resistance of Gramineae and soil type was mainly meadow chernozem. The Kunes River was a temperate continental climate type, which belongs to the seasonal snow melt water and rainwater recharge rivers, intra annual variation of small diameter. the length of $258 \mathrm{~km}$, the catchment area of $3532 \mathrm{~km}^{2}$, The annual average temperature of 8 degrees, the annual rainfall of about $800 \mathrm{~mm}$, The high temperature period is 7-8 months, and the precipitation concentration in 4-6 months, in May the most.

\section{Test design and sample collection}

The test set Native Grassland (NG), Grazed Grassland (GG), Six years conventional field (6-yr CF), More than twenty years conventional field $(20-y \mathrm{C} C F)$, Six years organic field (6-yr OF) and Thirteen years organic field (13-yr OF) Six treatments. Artificial disturbance of natural grassland is very small, most of the natural grassland has been cultivated for grazing grassland or over 20 years, Grazing period was mainly from September to June. The application of chemical fertilizer (pure nitrogen amount of about $170 \mathrm{~kg} / \mathrm{hm}^{2}$ ) in Conventional tillage models and The application of organic fertilizer (pure nitrogen amount of about $170 \mathrm{~kg} / \mathrm{hm}^{2}$ ) in organic cultivation. Soil samples in late September 2010 before the winter collection. Frist dig a pit (30 cm wide and $45 \mathrm{~cm}$ deep), and then in the $0-20 \mathrm{~cm}$ soil layer collection size consistent with the undisturbed soil sample (length $*$ width $*$ high $=20 \mathrm{~cm} * 10 \mathrm{~cm} * 10 \mathrm{~cm}$ ) and the sampling point as close as possible in the whole soil and bulk density of the samples nearby, to as much as possible to reduce the spatial variability of soil samples, In order to obtain the aggregate distribution of undisturbed soil sample determination. Each treatment takes three undisturbed soil samples, into the square plastic box and carefully transported to the laboratory. Then immediately soil samples screened out by $8 \mathrm{~mm}$ soil sieve and the large clods gently crushing along natural fractures, finally analysis of soil aggregates and stability in dried soil samples within the laboratory. 


\section{Research methods and measurement items}

The study accessed to the soil quality index dividing into soil physical, chemical and biological quality indexes of three types. The first was principal component analysis (PCA), and then was correlation analysis and t-test, which orders to determine the significant factors affecting soil quality changes. Soil aggregate separations use the wet sieving method. According to the above 8 particle size $\mathrm{mm}$ soil sieve samples were divided into the following categories: large aggregates $(2-8 \mathrm{~mm})$, smaller aggregates $(0.250$ $2 \mathrm{~mm})$, micro-aggregate $(0.053-0.25 \mathrm{~mm})$ and silt plus clay group $(<0.053 \mathrm{~mm})$. The soil samples were separated and arranged to determine the particle composition, soil organic carbon, total nitrogen and so on. The soil aggregate : $0.053 \mathrm{~mm}, 0.053-0.25 \mathrm{~mm}, 0.250-2$ $\mathrm{mm}<2-8 \mathrm{~mm}$ in turn representing as SAP1, SAP2, SAP3 and SAP4, and the particle size of the soil organic carbon content are expressed as SOC1, SOC2, SOC3 and SOC4, the content of soil organic carbon of $0-20 \mathrm{~cm}$ representing SOCT. The main indexes measuring methods are shown in Table 1. The AWCD and diversity index calculation methods are as follows:

(1) The average absorbance of AWCD can be used to estimate the total capacity of microbial community in the use of carbon sources. (Ai is the relative absorbance of $i$, and A A1 is the relative absorbance of A1.)

$$
\mathrm{AWCD}=\sum(\mathrm{Ai}-\mathrm{AA} 1) / 31
$$

(2) Shannon-Wiener richness index $\mathrm{H}$ was used to evaluate the species richness.

$$
\mathrm{H}=-\sum \mathrm{Pi} \cdot \ln (\mathrm{Pi})
$$

(3) Shannon-Wiener richness index E was used to evaluate the species richness. ( $\mathrm{S}$ is the number of the carbon source.)

$$
\mathrm{E}=\mathrm{H} / \ln \mathrm{S}
$$

(4) Shannon-Wiener advantage of D number is used to evaluate some of the most common species of a moderate.

$$
\mathrm{D}=1-\sum(\mathrm{Pi})^{2}
$$

\section{Statistical analysis}

Through the SPSS Base Ver17.0 statistical software (SPSS, Chicago, IL, USA) analysis correlation of the data. The multivariate methods such as principal component analysis (PCA) was employed to determine how the samples were different as a whole.

\section{Results and analyses}

\section{The influence of grassland development to soil physical quality index}

On soil physical quality index for PCA analysis (Fig. 1). The projection information indicates that the land use patterns are divided into three categories. The first category is organic farming for 6 years and 13 years. The second category is conventional farming for 6 years and 20 years. Others are processed as the third category. Using correlation analysis, 
of which the results reached a very significant level, for further description of influencing factors of the soil physical quality indicators are shown in Table 2. Soil physical indicator of $0.053-0.25 \mathrm{~mm}$ aggregates percentage and first principal component PC1 (principal component 1) is a significant positive correlation, 2-8 mm aggregates percentage and first principal component $\mathrm{PC} 1$ is a significant negative correlation. That means the positive direction of $\mathrm{PC} 1$ and $\mathrm{PC} 2$ spindle are organic farming mode. 0.25-2 mm aggregates percentage and second principal component $\mathrm{PC} 2$ is a significant positive correlation. That means the negative direction of PC2 spindle and the positive direction of $\mathrm{PC} 1$ spindle are conventional farming mode. The negative direction of PC1 and PC2 spindle are the third type of grass mode. Aggregates of particles percentage change indicate the effect of management measures under different land use patterns on soil aggregate. The positive direction of the first principal component is the percentage increase of $0.053-0.25 \mathrm{~mm}$ aggregates. The negative direction of it is the percentage increase of 2-8 $\mathrm{mm}$ aggregates. All this shows that the farmland management (organic and conventional) mode causes the macro-aggregates crushing and 0.053-0.25 mm micro-aggregates increasing and the grassland management mode is conducive to maintaining $2-8 \mathrm{~mm}$ macro-aggregates. The positive direction of the second principal component is the percentage increase of $0.25-2$ $\mathrm{mm}$ aggregates. This shows that the organic management mode is conducive to the formation of $0.25-2 \mathrm{~mm}$ aggregates, but the effect of its formation rate is less than the breakage rate of $0.053-0.25 \mathrm{~mm}$ aggregates. This indicates that after the grassland convert to cropland; farmland mode makes soil crush from macro-aggregates into 0.053-0.25 mm micro-aggregates and the overall degradation of soil physical quality. But organic farming management mode can alleviate soil particles' broken, which can make $0.25-2 \mathrm{~mm}$ macroaggregates increase.

Table 1. Main index measuring method

\begin{tabular}{|c|c|}
\hline Item & Measuring method \\
\hline Soil bulk (SB) & Cutting-ring method \\
\hline Soil $\mathrm{pH}$ value $(\mathrm{pH})$ & 2.5:1 water-soil ratio electrode \\
\hline Soil organic carbon (SOC) and total nitrogen (TN) & Analysis of carbon and nitrogen analyzer \\
\hline $\begin{array}{l}\text { Soil available phosphorus (AP) and total } \\
\text { phosphorus (TP) }\end{array}$ & MO Ti Sc colorimetry \\
\hline $\begin{array}{l}\text { Soil available potassium (AK) and total potassium } \\
\qquad(\mathrm{TK})\end{array}$ & Flame photometric determination \\
\hline Soil alkaline hydrolysis nitrogen (AN) & Alkali solution diffusion method \\
\hline $\begin{array}{c}\text { Soil ammonium nitrogen }\left(\mathrm{NH}_{4}{ }^{+}-\mathrm{N}\right) \text { and nitrate } \\
\text { nitrogen }\left(\mathrm{NO}_{3}^{-}-\mathrm{N}\right)\end{array}$ & Flow analyzer determination \\
\hline $\begin{array}{c}\text { Soil microbial carbon }(\mathrm{SMC}) \text { and soil microbial } \\
\text { nitrogen }(\mathrm{SMN})\end{array}$ & Chloroform fumigation extraction method \\
\hline Oxidized organic carbon (OOC) & Potassium permanganate oxidation colorimetry \\
\hline Hot water soluble organic carbon (HWSOC) & $\begin{array}{c}\text { Distilled water extraction and Potassium dichromate } \\
\text { titration }\end{array}$ \\
\hline Acid hydrolysis carbon (AOC) & $\begin{array}{l}6 \mathrm{M} \text { concentrated hydrochloric acid } \\
\text { extraction, Potassium dichromate titration }\end{array}$ \\
\hline Average color change rate of soil (AWCD) & Biolog analyzer determination \\
\hline $\begin{array}{c}\text { Soil fungi (SFUNG), Bacteria (SBACT) and } \\
\text { Actinomycetes Strain (SACTI) }\end{array}$ & Plate counting method \\
\hline
\end{tabular}




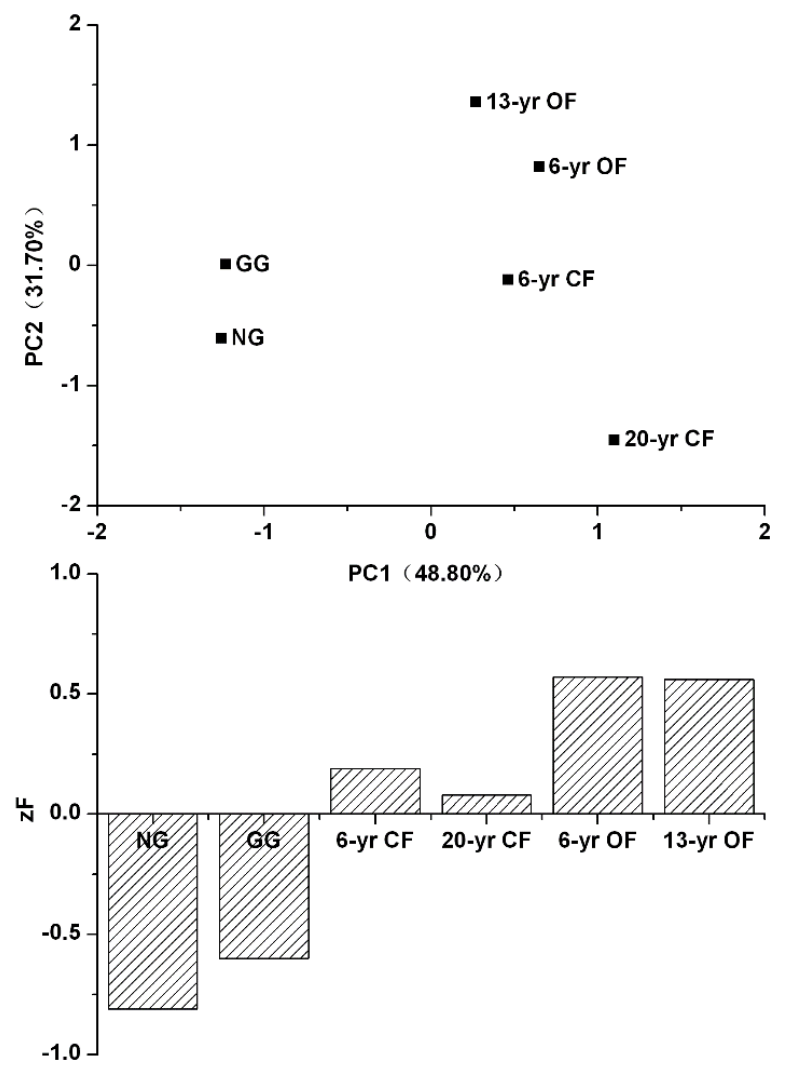

Figure 1. PCA of physics index and composite scores of soil quality. (zF indicates PCA of composite scores. The same below)

Table 2. Correlativity between physics index of soil quality

\begin{tabular}{c|c|c}
\hline Factor & PC1 & PC2 \\
\hline SB & 0.45 & 0.44 \\
SAP1 & 0.68 & -0.69 \\
SAP2 & $0.88^{* *}$ & -0.11 \\
SAP3 & 0.24 & $0.94^{* *}$ \\
SAP4 & $-0.98^{* *}$ & -0.15 \\
Eigenvalue & 2.442 & 1.584 \\
Contribution rate (\%) & 48.801 & 31.704 \\
Cumulative contribution rate (\%) & 48.801 & 80.505 \\
\hline
\end{tabular}

*Indicates significant difference $(p<0.05)$,**indicates extremely significant difference $(p<0.01)$. The same below

\section{The influence of grassland development to soil chemical mass index}

The PCA analysis (Fig. 2) on soil chemical mass, the projection information indicates that the land use patterns are divided into four categories, the first category includes six years of organic farming, 13 years of organic farming and six years of conventional farming, the second category is grazing meadow, the third category is natural grassland, and the fourth category is 20-year conventional tillage. Use correlation analysis can further indicates that soil chemical quality indicators 
influencing factors shown in Table 3, the correlation analysis results reach a significant level. First principal component PC1 and soil total nitrogen content of the soil chemistry indicators, $0.25-2 \mathrm{~mm}$ soil organic carbon content, $2-8 \mathrm{~mm}$ soil organic carbon content and soil organic carbon content are a significant positive correlation with soil potassium content, soil phosphorus content, $<0.053 \mathrm{~mm}$ soil organic of carbon content, 0.053-0.25 $\mathrm{mm}$ soil organic carbon content, namely that the positive direction of PC1 spindle are natural grass, 13 years of organic farming, 6 years of organic farming and 6 years of conventional farming; the second principal component PC2 and available potassium content was extremely significant with positive correlation with ammonium nitrogen content, and an acid solution of carbon content was significantly significant negative correlation, i.e. PC2 spindle positive direction represents natural grassland, 6 years of grazing grassland and six years of conventional tillage, the negative direction means 6 years of organic farming, 13 years of conventional tillage or 20 years beyond. The third principal component the PC3, active carbon dioxide content and hot water-soluble carbon content was significantly positively related. The positive direction of the PC3 spindle represents 6 years of conventional tillage, 6 years of grazing grassland and organic farming; therefore, the land use pattern can be divided into four main categories. Soil organic carbon and its components play an important role in many of the features in the soil, as it is considered to be an important indicator of soil quality. The positive direction of the first principal component represents the increase of soil total nitrogen content of the soil chemistry indicators, $0.25-2 \mathrm{~mm}$ soil organic carbon content, 2-8 $\mathrm{mm}$ soil organic carbon content, soil organic carbon content of soil potassium content, soil total phosphorus, $<0.053 \mathrm{~mm}$ soil increased organic carbon content, $0.053-0.25 \mathrm{~mm}$ soil organic carbon content. And it shows that soil organic carbon and soil total nutrient have the essential influence on soil chemical quality, especially soil organic carbon and total nitrogen reached a significant positive correlation, which decides the reaction of soil chemical quality to management measures in the land-use mode. The second principal component in the positive direction for the content of soil soluble potassium and ammonium nitrogen increases, the negative direction for the content of acid solution of carbon increases. It shows that the condition that at a certain level of total nutrient, soil available potassium, ammonium nitrogen and hydrolysable carbon content is most sensitive in the secondary impact factor. The field husbandry (organic and conventional) management model destroys soil aggregates, which made the physical protection of the nutrients reduced. Farmland management model led a significant reduction to the soil available potassium and ammonium nitrogen contents, but the content of acid hydrolysis organic carbon increased significantly. The third main component of the positive direction is the content of active carbon dioxide and hot-water-soluble carbon increases, indicating that under the six years of grazing and short-term farming mode (conventional farming and organic farming) the activity of carbon dioxide and hot water soluble carbon can get easily use. With the growth of the cultivation age, organic carbon which is easy to use gradually reduced. This indicates that after the grassland conversed to cropland, the total nutrient in the soil, organic carbon, active carbon dioxide and hot water-soluble carbon first increased under the short-term tillage. With the growth of cultivation age, the content of soil available potassium and ammonium nitrogen decrease significantly at first, and finally the quality of soil chemistry in the farmland all get decreased gradually. Because grazing pattern does not use any exogenous substances, the degradation of soil chemical quality is the most obvious. 


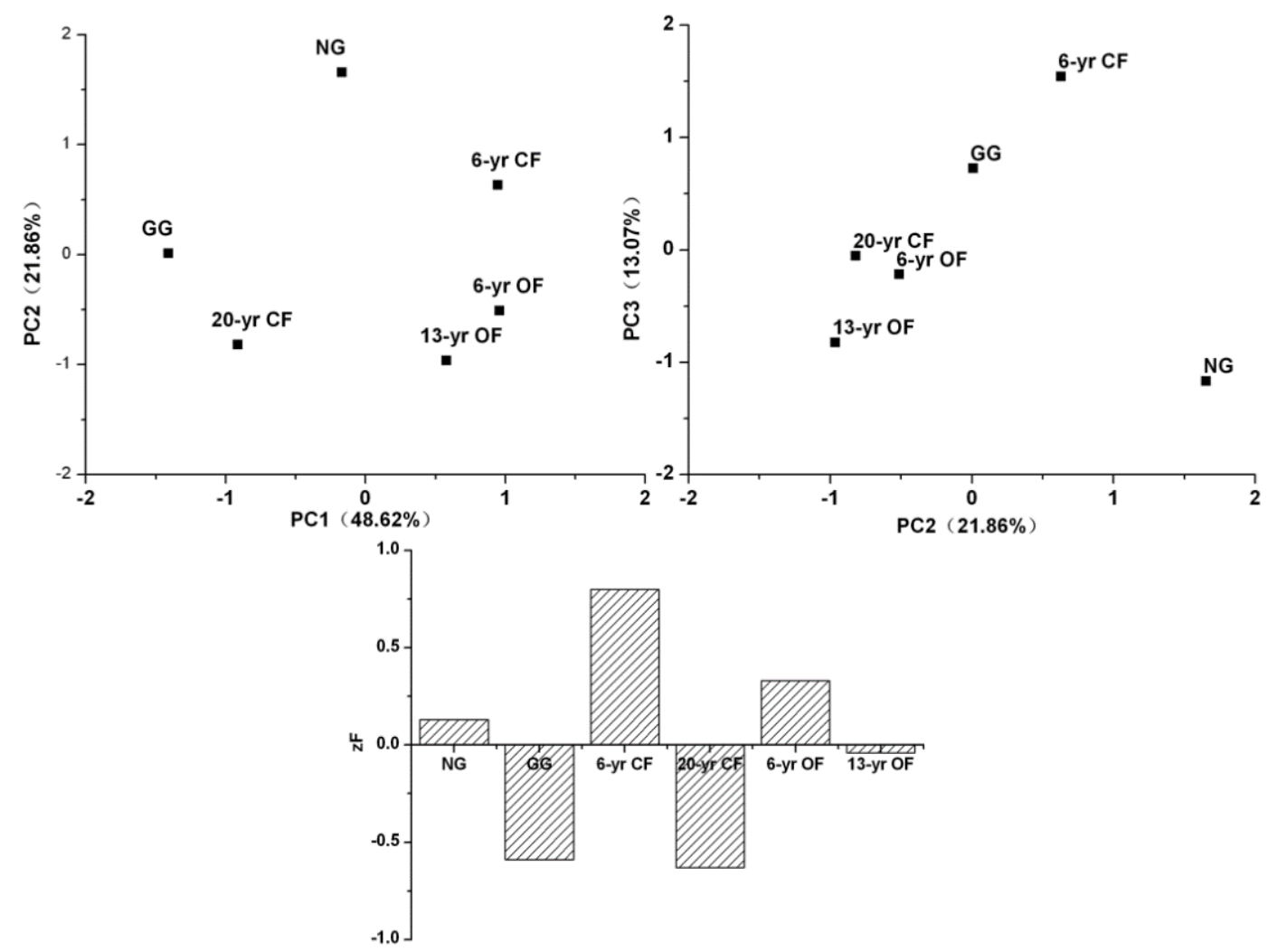

Figure 2. PCA of chemistry index of soil quality

Table 3. Correlativity between chemistry index of soil quality

\begin{tabular}{c|c|c|c}
\hline Factor & PC1 & PC2 & PC3 \\
\hline $\mathrm{pH}$ & 0.11 & -0.58 & -0.07 \\
$\mathrm{NH}_{4}{ }^{+}-\mathrm{N}$ & -0.17 & $0.80^{*}$ & 0.08 \\
$\mathrm{NO}_{3}{ }^{-\mathrm{N}}$ & 0.60 & 0.17 & 0.10 \\
$\mathrm{AN}$ & -0.61 & 0.14 & 0.60 \\
$\mathrm{AP}$ & 0.42 & -0.71 & -0.42 \\
$\mathrm{AK}$ & 0.13 & $0.90^{* *}$ & -0.26 \\
$\mathrm{TN}$ & $0.94^{* *}$ & 0.30 & -0.07 \\
$\mathrm{TK}$ & $0.76^{*}$ & -0.51 & 0.04 \\
$\mathrm{TP}$ & $0.76^{*}$ & 0.04 & 0.07 \\
$\mathrm{SOC} 1$ & $0.77^{*}$ & -0.14 & -0.56 \\
$\mathrm{SOC} 2$ & $0.80^{*}$ & 0.52 & 0.16 \\
$\mathrm{SOC} 3$ & $0.99^{* *}$ & 0.03 & 0.12 \\
$\mathrm{SOC} 4$ & $0.96^{* *}$ & 0.03 & 0.26 \\
SOCT & $0.96^{* *}$ & 0.16 & -0.18 \\
OOC & 0.29 & 0.03 & $0.82^{*}$ \\
HWSOC & 0.48 & -0.28 & $0.80^{*}$ \\
AOC & -0.06 & $-0.82^{*}$ & 0.22 \\
Eigenvalue & 8.269 & 3.716 & 2.221 \\
Contribution rate (\%) & 48.642 & 21.859 & 13.065 \\
Cumulative contribution rate (\%) & 48.642 & 70.501 & 83.567 \\
\hline
\end{tabular}




\section{The influence of grassland development to soil bio-quality index}

On soil biological quality index for PCA analysis (Fig. 3), the projection information indicates that the mode of land use is mainly divided into two categories, the first category for tillage (organic and conventional) mode, second kinds of grass mode, using correlation analysis further illustrate the soil biological quality index impact factors in Table 4, the results of correlation analysis at significant level. The first principal component $\mathrm{PC} 1$ and soil biological indicators of AWCD, microbial nitrogen content was significant positive correlation, namely $\mathrm{PC} 1$ spindle orientation for tillage (organic and conventional) mode, the negative direction for second kinds of grassland pattern; as a result of the second main components of PC2 and biological indicators of the quality of impact factors are not significant correlation exists, so on the mode of land utilization soil biological quality impact is very small. The first principal component is the direction for tillage (organic and conventional) model, AWCD and microbial nitrogen content increased, description of farming (organic and conventional) mode of microbial communities using carbon and microbial nitrogen capability is strong, namely farmland management pattern is enhanced by microorganisms on soil carbon and nitrogen utilization ability, relatively speaking, grassland management model for carbon and nitrogen resources conservation. Suggesting that the conversion of grassland to farmland, farmland tillage mode to promote soil microorganisms on carbon and nitrogen resource utilization ability, is not conducive to the soil carbon and nitrogen retention.
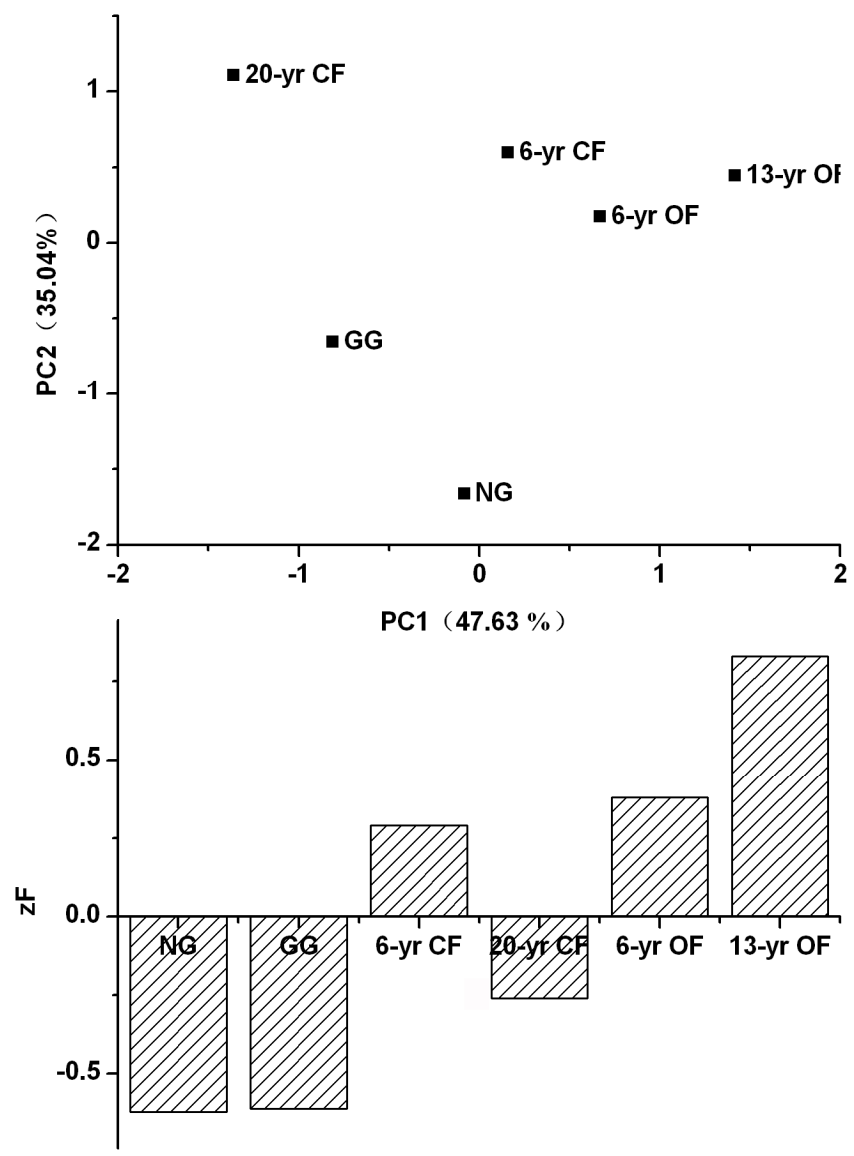

Figure 3. PCA of biology index of soil quality 
Table 4. Correlativity between biology index of soil quality

\begin{tabular}{c|c|c}
\hline Factor & PC1 & PC2 \\
\hline SFUNG & 0.73 & -0.6 \\
SBACT & 0.65 & -0.58 \\
SACTI & 0.58 & -0.69 \\
AWCD & $0.97^{* *}$ & 0.14 \\
H & 0.53 & 0.74 \\
E & -0.57 & 0.35 \\
D & 0.51 & 0.75 \\
SMC & 0.63 & 0.33 \\
SMN & $0.92^{* *}$ & 0.32 \\
Eigenvalue & 4.286 & 3.154 \\
Contribution rate (\%) & 47.626 & 35.041 \\
Cumulative contribution rate (\%) & 47.626 & 82.667 \\
\hline
\end{tabular}

\section{Discussion}

\section{Soil physical quality index}

The analysis and ordination diagram of the principal component of the soil physical quality indicators can reflect the reaction of the soil physical quality due to the change of the land management practices. As the lawn developed to different form with different pattern of land usage, the $0.053-0.25 \mathrm{~mm}, 0.25-2 \mathrm{~mm}, 2-8 \mathrm{~mm}$ soil aggregates experience significant influence. With the pattern of grassland turns to be conventional or organic farmland, $2-8 \mathrm{~mm}$ soil macro aggregate has broken into the smaller micro aggregate, which is consistent with the former research that the water stable aggregate in natural grassland, forest land and grazing grassland are much higher than the farmlands' (Kremer and Kussman, 2011; Kremer and Li, 2003; Guo et al., 2010).

The increase of $0.25-2 \mathrm{~mm}$ soil aggregate is the important reflecting for a stability tend of the basic substance in soil and its function unit (Jastrow, 1996; Puget et al., 2000; Six and Elliott, 1998). The results show that the $0.25-2 \mathrm{~mm}$ soil aggregate increases gradually in organic farming at the year of 6 and 13, and the $0.25-2 \mathrm{~mm}$ soil aggregate decreases gradually in conventional tillage beyond the year of 6 and 20, it may be directly related to the fresh organic material who return back to the soil (Chen et al., 2016; Cole et al., 1993). This shows that organic farming mode is favorable to optimize the soil aggregate's structure. Therefore, land use patterns are determined to be the major factor of soil physical quality under the premise of same climate, same terrain and same soil property. Soil management behavior can future reflects the good or bad of soil physical property.

\section{Soil chemical quality index}

Land use and management measures changed the natural grassland soil chemical characteristics, organic farming mode soil chemistry quality is best, conventional tillage 20 years of soil chemistry quality relative worst, the most sensitive chemical quality index is soil total nitrogen and organic carbon $(\mathrm{P}<0.01)$, especially $0.25-2 \mathrm{~mm}$ and $2-$ $8 \mathrm{~mm}$ soil organic carbon content $(\mathrm{P}<0.01)$. Conventional farming mode weakened the soil structure, and lead to soil organic carbon and total nitrogen significantly reduced 
(Jacobs et al., 2009; Koch and Stockfisch, 2006), this may be as cultivation increased soil organic matter mineralization rate relevant (Blair et al., 2006), but organic farming mode organic material not only directly for aggregate function to provide cementing material, compensation soil mineralization, carbon and nitrogen loss, and for soil biological activity provide energy, promoting the soil large aggregate and micro aggregate composition and the stability of the organic matter (Alagoz and Yilmaz, 2009).

At the same time, land use and management measures first cause, total content of soil nutrients and soil organic carbon content changes $(\mathrm{P}<0.01)$, the second is ammonium nitrogen $(\mathrm{P}<0.05)$ and phosphorus and potassium content $(\mathrm{P}<0.01)$, and the last is easy oxidation of organic carbon and thermal hydrolysis organic carbon content $(\mathrm{P}<0.05)$. There have been many literature compared the land use and management measures on soil chemical quality index influence, considered that soil organic carbon, total nitrogen, available phosphorus, $\mathrm{pH}$ and vulnerable to agronomic measures influence (Voundi and Tonye, 2003; Nosrati et al., 2011), but not for land use and management measures to the chemical quality index of influence sorting, this may and soil chemical properties vulnerable to soil environmental change and crop management measures about influence (Paudel et al., 2012).

\section{Soil bio-quality index}

The principal component analysis and correlation analysis interpret the influence of land use and regulative measure to soil bio-quality index, which changes the value of soil microorganism's ability of utilization from carbon source AWCD $(p<0.01)$ and the content of nitrogen in microbial biomass $(p<0.01)$, and both the influence from the two numerical value of tillage pattern (organic and conventional) are larger than the figure from grass pattern. Via an analysis of utilization ability on soil microbial biomass carbon source by Juliet (Juliet et al., 2002) and Cooksona (Cooksona et al., 2008), they also told planting pattern has a big effect on soil microorganism. Applying organic materials can stimulate microbial activity (Tian et al., 2016), applying chemical fertilizer has a little effect on soil microbial activity and microbial biomass (Lovella et al., 1995); however, the long-term applying chemical fertilizer may decrease soil microbial activity (Li et al., 2017). Thus, soil microbial activity can be enhanced when the grassland exploited to the farmland. But the soil microbial activity whose usage is beyond 20 years by conventional tillage decrease, the farmland need fertilization reasonable in order to optimize the environment of soil microorganism and maintain soil microbial activity.

\section{Conclusion}

The effect of land use patterns on soil physical quality is more influential than the land management measures, the farmland cultivation mode break the soil macroaggregate to $0.053-0.25 \mathrm{~mm}$ smaller microaggregate, but the organic farming management mode can alleviate soil particle crushing and increase the number of 0.25 $2 \mathrm{~mm}$ macroaggregate.

After the grassland being conversed to the farmland, total soil nutrient, organic carbon, activated carbon oxide and hot water soluble carbon will get much increase in a short-term cultivation mode. But the content of soil available potassium and ammonium nitrogen will get reduced significantly along with the increasing cultivation time, and 
finally the soil chemistry quality index of farmland are all decreasing generally. For grazing mode, as it does not use any foreign matter, the degeneration of soil chemical mass will be much more to see.

After the grassland being conversed to the farmland, the farmland cultivation mode stimulate the soil microorganism's ability of absorbing carbon and nitrogen, which goes against the soil carbon and nitrogen's conservation especially for a long-term fertilizer application in the regular farming mode.

Acknowledgements. Science and Technology Support Program of Xinjiang Production and Construction Corps (2018AA005), the National key research and development program of China (2016YFC0501406), This research was supported by the National Natural Science Foundation of China (31560169), the International Science \& Technology Cooperation Program of China (2015DFA11660), and Shihezi University level project (GJHZ201706, GJHZ201802).

\section{REFERENCES}

[1] Alagoz, Z., Yilmaz, E. (2009): Effects of different sources of organic matter on soil aggregate formation and stability: a laboratory study on a Lithic Rhodoxeralf from Turkey. - Soil Tillage Research 103: 419-424.

[2] Blair, N., Faulkner, R. D., Till, A. R., Korschens, M., Schulz, E. (2006): Long-term management impacts on soil C, N and physical fertility: Part II: Bad Lauchstadt static and extreme FYM experiments. - Soil Tillage Res 91: 39-47.

[3] Chen, G. Q., Jiang, M. M., Yang, Z. F., Chen, B., Zhou, J. B. (2008): Exergetic assessment for ecological economic system: Chinese agriculture. - Ecological Modeling 220(3): 397-410.

[4] Chen, Z., Guo, Y. B., Du, Z. L., Wu, W. L., Meng, F. Q. (2016): Change in the abundance and community composition of ammonia-oxidizing bacteria and archaea at soil aggregate level as native pasture converted to cropland in a semiarid alpine steppe of central Asia. - Journal of Soils and Sediments 16(1): 243-254.

[5] Cole, C. V., Flach, K., Lee, J., Sauerbeck, D., Stewart, B. (1993): Agricultural sources and sinks of carbon. - Water Air Soil Pollut 70: 111-122.

[6] Cooksona, W. R., Daniel, V. M., Margaret, M. R. (2008): Characterizing the relationships between soil organic matter components and microbial function and composition along a tillage disturbance gradient. - Soil Biology and Biochemistry 40(3): 763-777.

[7] Fermont, A. M., van Asten, P. J. A., Giller, K. E. (2008): Increasing land pressure in East Africa: the changing role of cassava and consequences for sustainability of farming systems. - Agriculture, Ecosystems and Environment 128: 239-250.

[8] Guo, Z. B., Yan, G. J., Zhang, R. H., Li, F. M. (2010): Improvement of soil physical properties and aggregate-associated $\mathrm{C}, \mathrm{N}$, and $\mathrm{P}$ after cropland was converted to grassland in semiarid Loess Plateau. - Soil Sci 175: 99-104.

[9] Jacobs, A., Rauber, R., Ludwig, B. (2009): Impact of reduced tillage on carbon and nitrogen storage of two Haplic Luvisols after 40 years. - Soil Tillage Res 102: 158-164.

[10] Jastrow, J. D. (1996): Soil aggregate formation and the accrual of particulate and mineralassociated organic matter. - Soil Biol. Biochem 28: 656-676.

[11] Juliet, P. M, Lynne, B., Randerson, P. F. (2002): Analysis of microbial community functional diversity using sole-carbon-source utilisation profiles-acritique. - FEMS Microbiology Ecology 42(1): 1-14.

[12] Koch, H. J., Stockfisch, N. (2006): Loss of soil organic matter upon ploughing under a loess soil after several years of conservation tillage. - Soil Tillage Res 86: 73-83.

[13] Kremer, R. J., Kussman, R. D. (2011): Soil quality in a pecan-Kura clover alley cropping system in the Midwestern USA. - Agroforestry Systems 83: 213-223. 
[14] Kremer, R. J., Li, J. (2003): Developing weed-suppressive soils through improved soil quality management. - Soil Till Res 72: 193-202.

[15] Li, R., Tao, R., Ling, N., Chu, G. X. (2017): Chemical, organic and bio-fertilizer management practices effect on soil physicochemical property and antagonistic bacteria abundance of a cotton field: Implications for soil biological quality. - Soil \& Tillage Research 167: 30-38.

[16] Lovella, R. D., Jarvisa, S. C., Bardgettb, R. D. (1995): Soil microbial biomass and activity in long-term grassland: effects of management changes. - Soil Biology and Biochemistry 27(7): 969-975.

[17] Meriles, J. M., Vargas Gil, S., Conforto, C., Figoni, G., Lovera, E., March, G. J., Guzmán, C. A. (2008): Soil microbial communities under different soybean cropping systems: Characterization of microbial population dynamics, soil microbial activity, microbial biomass, and fatty acid profiles. - Soil Tillage Research 103(2): 271-281.

[18] Nosrati, K., Feiznia, S., Van Den Eeckhaut, M., Duiker, S. W. (2011): Assessment of soil erodibility in Taleghan Drainage Basin, Iran, using multi variate statistics. - Physical Geography 32(1): 78-96.

[19] Paudel, B. R., Udawatta, R. P., Kremer, R. J., Anderson, S. H. (2012): Soil quality indicator responses to row crop, grazed pasture, and agroforestry buffer management. Agroforestry Systems 84(2): 311-323.

[20] Puget, P., Chenu, C., Balesdent, J. (2000): Dynamics of soil organic matter associated with particle-size fractions of water-stable aggregates. - Eur. J. Soil Sci 51: 595-605.

[21] Six, J., Elliott, E. T. (1998): Aggregation and soil organic matter accumulation in cultivated and native grassland soils. - Soil Science Society of America 62: 1367-1377.

[22] Tian, X, M., Zhang, F. H., Li, J. H., Fan, H., Cheng, Z. B., Wang, K. Y. (2016): Effects of bio-organic fertilizer on soil microbiome against Verticillium dahlia. - Int. J. Agric. Biol. 18(5): 923-931.

[23] Voundi, N. J. C., Tonye, J. (2003): Assessment of certain soil properties related to different land-use systems in the Kaya watershed of the humid forest zone of Cameroon. - Land Degradation and Development 14: 57-67.

[24] Yang, Y., Zhang, H. Q. (2009): Analysis of land use and land cover change in the Yili Newly reclaimed area in recent 20 years (in Chinese). - Resources Science 31(12): 20292034. 